\title{
RECENT DEVELOPMENT IN SEISMIC DESIGN OF REINFORCED CONCRETE BUILDINGS IN JAPAN
}

\author{
H. Aoyama1
}

This paper was pesented as a keynote address at the Pacific Conference on Earthquake Engineering, Auckland, November 1991.

\section{SUMOKARY}

\begin{abstract}
Japan experienced a quick development of highrise reinforced concrete frame-type apartment building construction, about 30 stories high, in the last decade. Outline of this development is first introduced in terms of planning of buildings, materials, construction methods, earthquake resistant design and dynamic response analysis. This quick development was made possible by, among others, the available high strength concrete and steel. In an attempt to further promote development of new and advanced reinforced concrete building structures, a five-year national project was started in 1988 in Japan, promoted by the Building Research Institute, Ministry of Construction. Outline of this project is introduced in the second part of this paper. It aims at the development and use of concrete up to $120 \mathrm{MPa}$, and steel up to $1200 \mathrm{MPa}$.
\end{abstract}

\section{INTRODUCTION}

The Building Standard Law in Japan provides design seismic loadings and principal design procedures for buildings up to $60 \mathrm{~m}$ in height. Structural design of any building with the height in excess of $60 \mathrm{~m}$ is subjected to the review of the structural Review Committee for Highrise Buildings of the Building Center of Japan, and subsequently a special permit by the Minister of Construction is issued.

As far as reinforced concrete (RC) buildings are concerned, the height had been limited to about $20 \mathrm{~m}$ in practice by means of administrative guidance. Any building taller than, say, seven stories had to be constructed by steel structure or composite steel and reinforced concrete (SRC) structure. This administrative guidance was a traditional one, stemming out from public distrust on the seismic resistance of concrete structures ever since 1925 Kanto Earthquake.

In the recent ten years or so, this trend has changed rapidly. There are currently various movements towards the higher RC construction. Among them, the most remarkable is the increase of highrise RC frame construction. Kajima construction Co. broke out the movement. They completed the first highrise RC, an 18-story apartment building, in 1974, followed by another 25-story apartment building in 1980. These highrise buildings were realized after a long and extensive effort in research and development of the company. Other construction companies followed, and the number of concrete buildings increased together with the increase of building construction.

Figure 1 shows the amount of annual highrise construction in Japan, which is the number of annual reception by the Building center for the review of the committee for Highrise Buildings. The figure also shows number of SRC and RC buildings in each year. Total number in each year varies from less than 10 to more than 100, according to economic fall and rise. Concrete construction takes about 23 percent on the average, however more than half of it is taken up by $R C$ in recent years.

The quick development of highrise RC construction owes to many things, but availability of high strength materials was evidently the most fundamental factor. In an attempt to further promote development of new and advanced type of RC construction, the Ministry of Construction started in 1988 a national five year research project entitled "Development of Advanced Reinforced Concrete Buildings using High-strength Concrete and Reinforcement" (usually referred to as "New RC"). This is a very ambitious project, which will probably lead to the realization of highrise RC buildings up to 60 stories, and buildings with wider spans, allowing for use in greater variety.

This paper introduces, in the first half, 


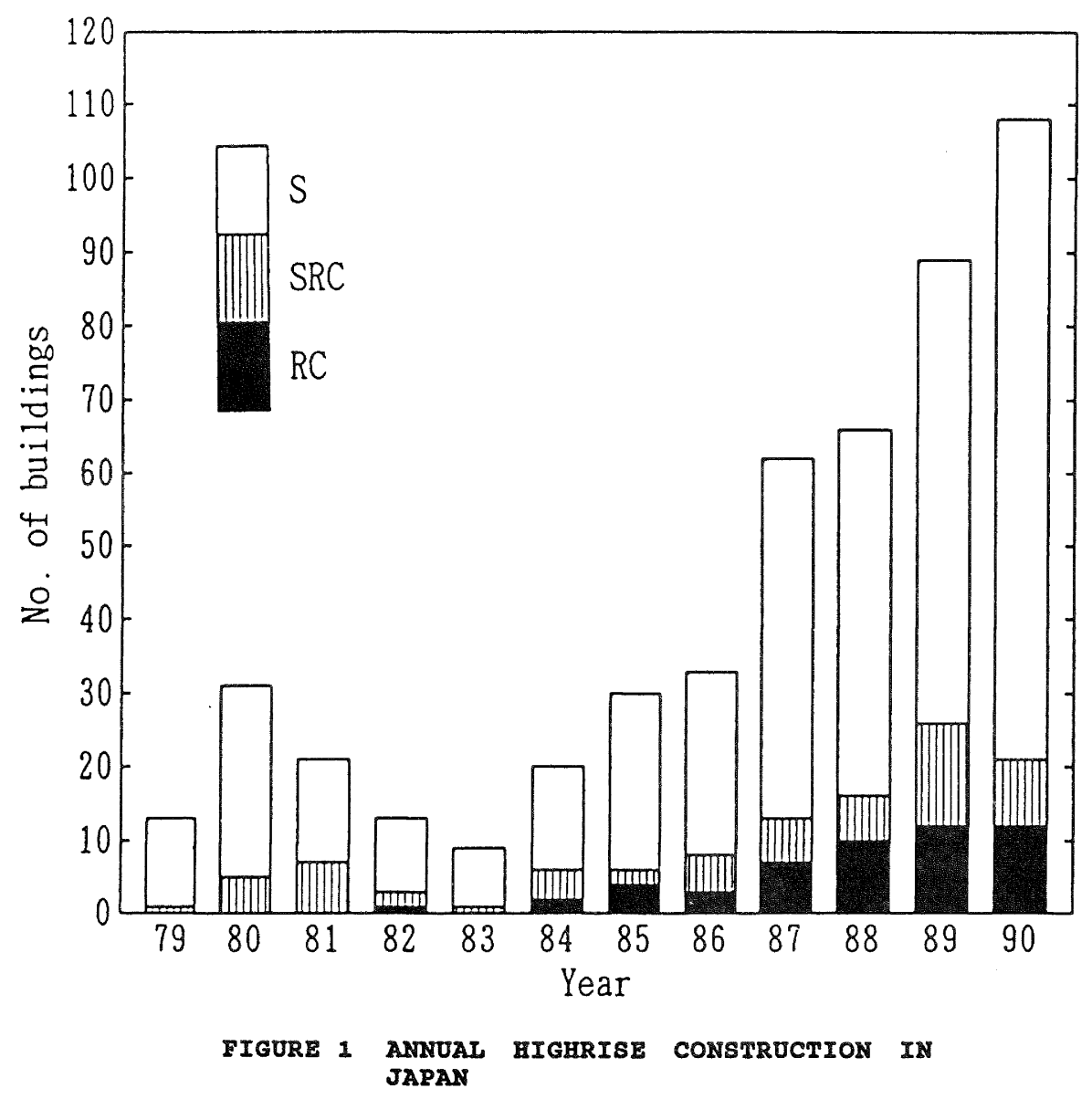

the current state-of-the-art of structural design of highrise RC buildings, and in the second half, the outline of the New RC national project of the Ministry of Construction.

\section{STRUCTURAL PLANNING AND MATERIALS FOR HIGHRISE RC BUILDINGS}

\section{Floor Plan and Elevation}

Highrise RC frame construction, currently, is used exclusively for apartment houses, because of better habitability provided by concrete. Floor plan of these buildings is generally regular, and symmetric with respect to one or two axes. In almost all cases, all frames in both directions are designed as moment resisting frames. Span length is around $5 \mathrm{~m}$, which is shorter than SRC or steel buildings. The small span is adopted in order to limit the axial load on a column, and thereby reduce the seismic force acting on a column.

The number of stories of the highrise RC buildings ranges from 20 to 40 stories. The story height is about $3 \mathrm{~m}$, which is also very small, permissible only for residential buildings. The frame elevation is generally quite regular, avoiding sudden change or discontinuity of stiffness in the vertical direction. Most buildings have one-story basement, and the foundation is supported, in most cases, by bearing piles of cast-in-place concrete.
Most of these highrise RC buildings consist of frames only, in two directions. Very few of them have shear walls in one or two directions. The main reason for not using shear walls is to avoid complexity in analysis, design and construction by the introduction of shear walls.

\section{Framing Kembers}

Column section is usually square, with the maximum dimension of about $90 \mathrm{~cm}$ at the base of buildings. Axial reinforcement ratio is about 2 to $3 \%$. To provide effective confinement to the core concrete, columns are provided with one or two of the following types of lateral reinforcement: rectangular or circular spirals, flush butt (FB) rings, closed sub-hoops, high strength deformed PC steel with $1275 \mathrm{MPa}$ yield stress (Urbon), or welded wire fabric.

To overcome large seismic overturning moment which produces dominating axial forces in the exterior columns in lower stories, additional axial bars (core bars) are frequently located in the central portion of these column sections.

Beams are of rectangular sections with relatively large width. Four-leg stirrups are generally used. Urbon stirrups are often used to increase shear resistance.

\section{Materials}

All highrise RC buildings use concrete with 
specified strength much higher than ordinary buildings. In the lowest portion either 36 or $42 \mathrm{MPa}$ concrete is used. Even stronger concrete, for example $48 \mathrm{MPa}$, is sometimes used. Strength is gradually reduced in upper stories. Lightweight concrete is not used.

The use of high strength and large size reinforcing bars is indispensable for highrise RC construction. Longitudinal bars up to 41 mm diameter (D41) with $390 \mathrm{MPa}$ yield stress are used. Lateral reinforcement consists of either D16 bars of $295 \mathrm{MPa}$ steel or high strength deformed PC bars with 1295 MPa yield stress (Urbon).

\section{EARTHOUAKE REBISTANT DESIGN AND RESPONSE ANALYSI8}

\section{Design principles and procedures}

As the basic principle of earthquake resistant design, beam hinge mechanism, or strong column-weak beam mechanism, is always assumed. Column hinges are allowed at the bottom of the first story and the top of the uppermost story, and at the exterior columns in the tension side of the lower stories. The beam hinge mechanism is assumed in order to provide large energy dissipating capacity distributed all around the structure.

Earthquake resistant design criteria are summarized in Table 1. These criteria are similar to those for steel or SRC highrise buildings with the height in excess of $60 \mathrm{~m}$. They are not explicitly stipulated in the Building standard Law. They have been traditionally used in the review by the Building center of Japan, as a kind of current consensus among structural engineers.

The design procedure consists of two phases, which essentially correspond to the two levels in Table 1. The first phase design is to protect the "weak links" of the structure, that is, yield hinge locations assumed in the mechanism, from forming yield hinges under the action of level 1 earthquake. For this purpose, design seismic loads are determined, usually referring to Building standard Law and preliminary earthquake response analysis, and members are proportioned to carry forces resulting from the design seismic loads.

The second phase design is to ensure the assumed mechanism to form under the action of level 2 earthquake. Collapse load associated with the mechanism formation is calculated, which is similar in definition as the ultimate load carrying capacity in the Building standard Law. It is generally required that this load level exceeds at least one and half times the design seismic loads. Structural members outside yield hinges are proportioned to forces associated with the mechanism formation enhanced by appropriate magnification factors.

A series of nonlinear time history earthquake response analysis are performed to confirm the design criteria in Table 1

\section{Design seismic Loading}

Current Building standard Law provides design seismic forces for buildings up to 60 $m$ in height only. However, it is a common practice for structural engineers to just extrapolate the provision of Building standard Law, and modify as needed, by a preliminary earthquake response analysis.

Figure 2(a) shows the design base shear coefficient of highrise RC buildings against the fundamental natural period from an equation stipulated in the Law, i.e.

$$
\mathrm{T}_{1}=0.02 \mathrm{~h}
$$

where $h$ is building height in $\mathrm{m}$. Most design falls above the code curve for second class (intermediate) soil. Figure $2(\mathrm{~b})$ shows the design base shear coefficient against calculated elastic fundamental natural period. The range shown by dotted curves corresponds to most highrise construction in Japan, either steel or SRC construction. It seems highrise RC buildings have slightly lower base shear, as long as they are compared on the basis of elastic natural period. Probably it would be a more fair comparison to take natural period based on cracked sections, although it is not a common practice to do so in Japan.

TABLE 1 EARTHQUARE RESISTANT DESIGN CRITERIA

Seismic hazard level

Probability of recurrence

Maximum ground velocity

(in Tokyo, $80 z$ in Osaka)

Member forces

Story ductility factor

Member ductility factor

story drift angle
Level 1

Once in lifetime

$25 \mathrm{~cm} / \mathrm{s}$

Concrete cracks but no steel yields

less than 1

less than 1

less than $1 / 200$
Level 2

Possible maximum $50 \mathrm{~cm} / \mathrm{s}$

Steel yields but no building collapses

less than 2

less than 2

less than $1 / 100$ 


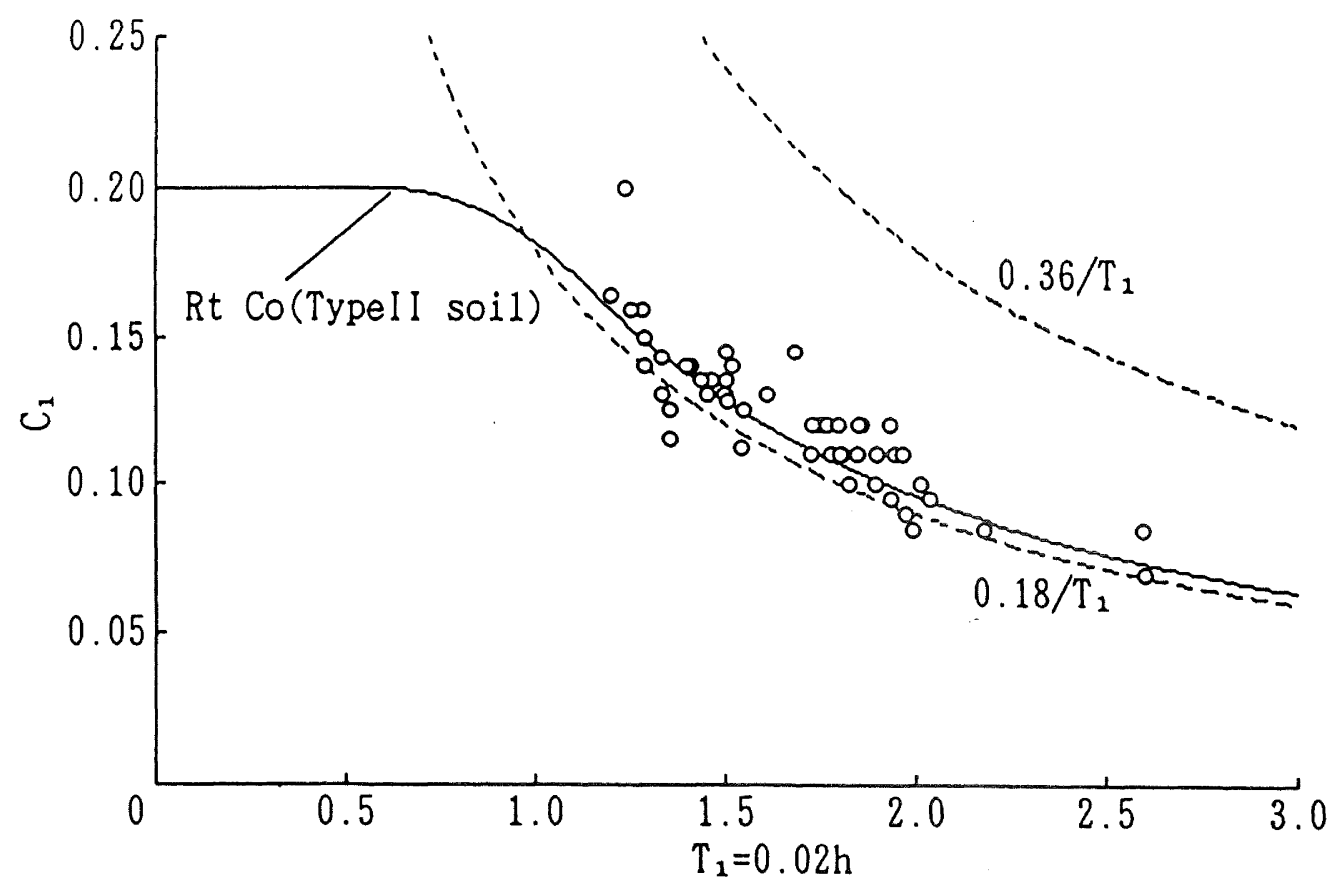

(a) Fundamental period from Code equation

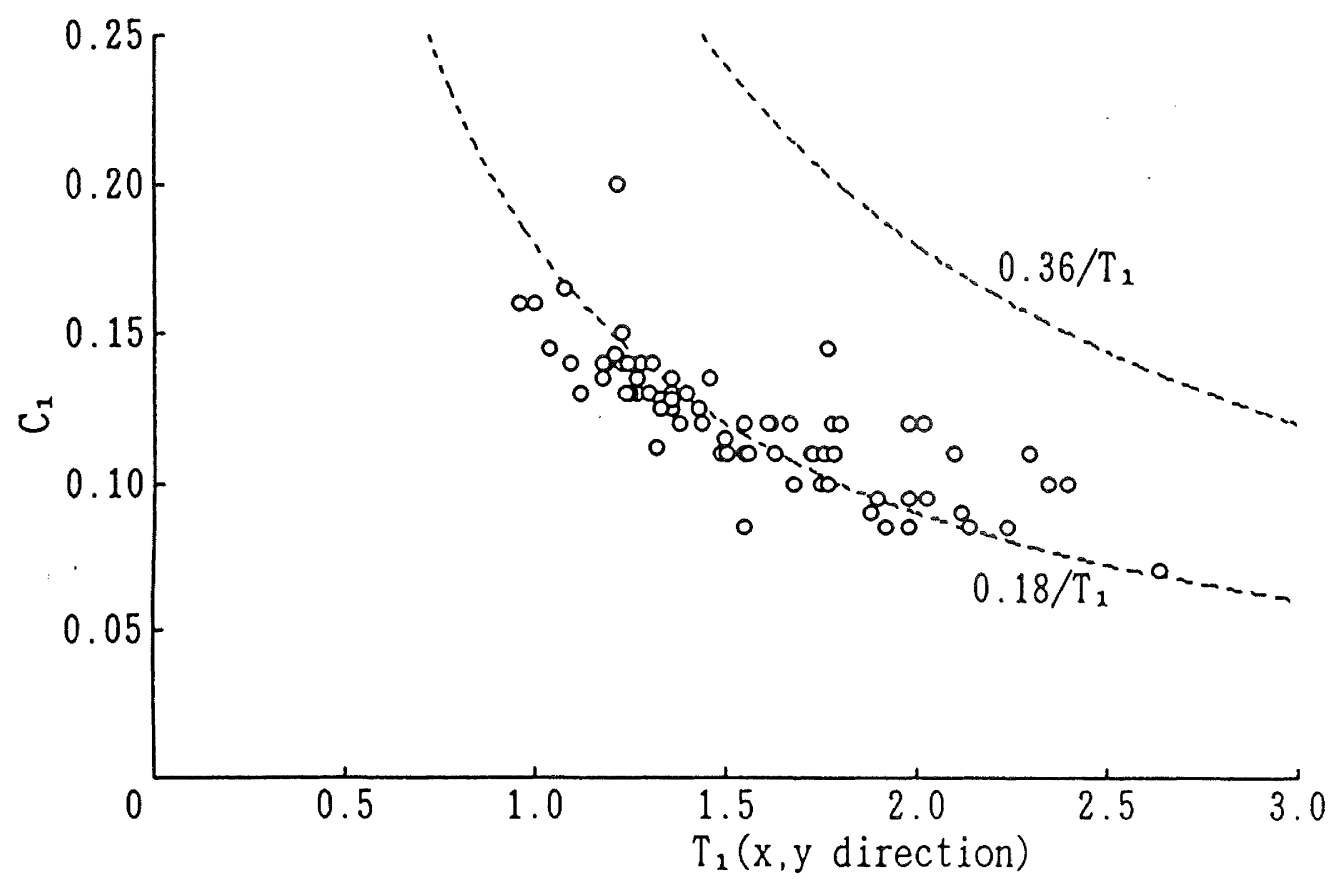

(b) Fundamental period from analysis

FIGURE 2 RELATIONSHIP BETWEEN BASE SHEAR COEFFICIENT AND FUNDAMENTAL NATURAL PERIOD

\section{First Phase Design}

The first phase design consists of structural analysis for design loads and proportioning of members. Structural analysis is carried out for permanent loading as well as design earthquake loading. Computer analysis is normally performed using displacement method, based on the uncracked section, considering flexural, shear and axial deformation of members, and rigid zones at member ends.
When the structure is susceptible to torsional deformation, three-dimensional frame analysis is carried out.

Moment redistribution is applied in some cases, although it is not widely used. The amount of moment redistribution is usually modest, and its appropriateness is demonstrated in the subsequent nonlinear frame analysis, so that no yield hinges would occur under the action of design seismic loads. 


\section{Second Phase Design}

The second phase design consists of evaluating the ultimate load carrying capacity, and to ensure the formation of assumed mechanism. The ultimate load carrying capacity may be evaluated by limit analysis. However, nonlinear incremental frame analysis is usually performed, which gives not only ultimate capacity but also the primary load-displacement relation for each story for use in the dynamic earthquake response analysis.

For the calculated member forces associated with the mechanism, ultimate strength of each member is investigated whether the assumed mechanism would be actually formed. This consists of the following three points:

(1) Beam ductility. Shear strength of beams must be sufficient to prevent premature shear failure. At the same time, beam end zones must be designed for yield hinges with sufficient rotation capacity. Bond splitting failures must also be prevented. The recent publication of "Design Guidelines for Earthquake Resistant Reinforced Concrete Buildings. Based on Ultimate Strength Concept [2]" is gradually getting popularity among practising engineers.

(2) Column strength and ductility. Except where yield hinges are expected to occur, columns should be protected against flexure and shear. A practical problem in this respect is how to determine design forces. Forces determined in the inelastic frame analysis correspond to predetermined load profile, but forces during dynamic excitation are subjected to much fluctuation due to ratio of upper and lower story drift, usually referred to as higher mode effect. Furthermore columns must be protected against forces coming from beams in two directions. The Guidelines [2] is serving for practice in this regard also.

(3) Beam-column joints. Prevention of premature joint failure is achieved by restricting shear stress in the connection, and by restricting bond stress along the beam bars passing through the joint. For exterior beam-column joints, beam bar anchorage is checked and is carefully detailed.

\section{Earthquake Response Analysis}

Reinforced concrete structures start cracking at a relatively low level of loading. Hence the elastic linear analysis based on the uncracked section serves little in predicting actual behaviour. As a simplified analytical model for nonlinear analysis, a lumped mass shear model is almost exclusively used in the time history dynamic response analysis for both level 1 and level 2 earthquake ground motions.

The restoring force characteristics of stories are defined by simplifying the load-displacement relation from incremental frame analysis into an equivalent trilinear relation. Degrading trilinear model or Takeda model are used for hysteresis rules under reversal.

In some cases, so-called flexural shear model is used, in which flexural deformation of overall structure due to overturning moment is separately evaluated and added to the shear deformation which is the frame deformation. The flexural deformation is evaluated on the basis of linear elasticity.

When the building is susceptible to torsional vibration, a dynamic quasi-three-dimensional model is used in the response analysis, which consists of many shear models, or flexural shear models. corresponding to each frame interconnected by rigid floor diaphragms.

One of the serious drawbacks of shear models is that it cannot predict member ductility factor. Usually it is evaluated indirectly by equating dynamic story drift to the static one in the incremental frame analysis. However, some engineers opt to carry out dynamic frame analysis where inelastic deformation of constituent frame members are directly accounted for in the time history earthquake response analysis.

As for the input earthquake ground motions, the Building Center of Japan recommends the use of waveforms in the following three categories [3] for any highrise buildings:

(1) Well known "standard" motions, e.g. El Centro 1940 NS and Taft $1952 \mathrm{EW}$.

(2) Records taken at nearby stations, e.g. Tokyo 1011956 NS for buildings in Tokyo.

(3) Records containing relatively long period components, e.g. Hachinohe 1968 NS and EW, Sendai TH 0301978 NS and EW.

Earthquake motions are normalized in terms of maximum velocity to the levels as prescribed in Table 1 . In many cases, design criteria for story drift angle in Table 1 are found to be the governing criteria.

\section{NATIONAL PROJECT ON ADVANCED RC BUILDINGS}

\section{Range of Material strength}

The quick development of highrise RC construction owes to many things, but development of the use of high strength concrete and high strength, large size reinforcing bars was evidently the most fundamental factor. In an attempt to further promote development of new and advanced RC construction, a national project lasting five years was started by the Ministry of Construction in 1988 [1]. The project was officially named as "The project on Development of Advanced Reinforced Concrete Buildings using High-strength Concrete and Reinforcement", but it is usually referred to as "New RC Project".

The range of material strength set out as the target of this project is shown in 


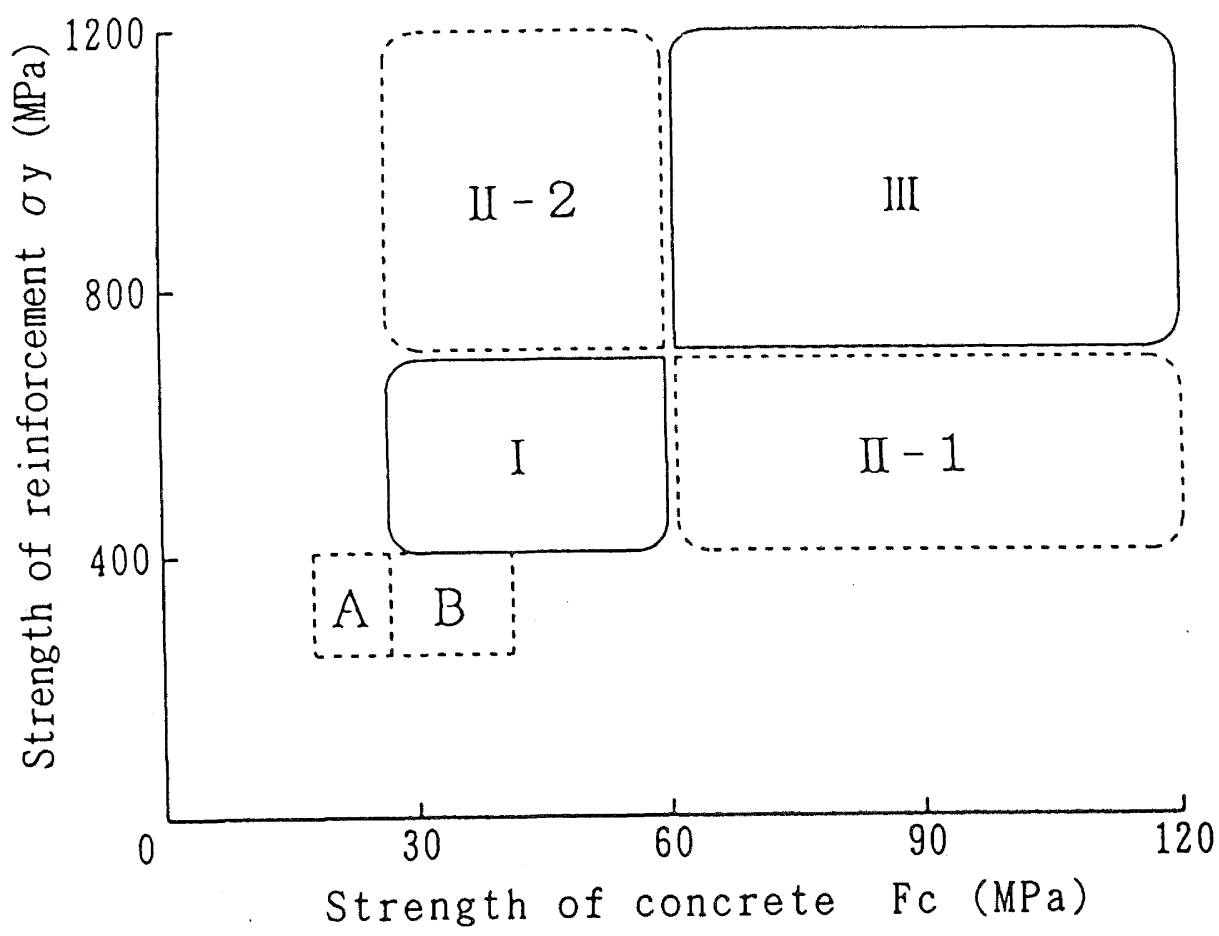

Zone : Type of RC buildings \& materials

A : Low-rise buildings

B : High-rise buildings

I : High-strength concrete \& reinforcement

II-1 : Ultra high-strength concrete \& high-strength reinforcement II-2 : High-strength concrete \& ultra high-strength reinforcement III : Ultra high-strength concrete \& reinforcement

FIGURE 3 STRENGTH OF MATERIALS AND FIELDS OF RESEARCH AND DEVELOPMENT

Figure 2. The vertical axis shows the yield strength of steel bars, and the horizontal axis shows the compressive strength of concrete. Small zones A and B in the figure surround by dotted lines correspond to the ranges for ordinary RC buildings and highrise RC buildings, respectively. As seen in the figure the currently used materials for highrise RC buildings occupy only small zones.

In contrast, the ranges of strength for concrete and steel are much larger. Concrete from 30 to $120 \mathrm{MPa}$ and steel from 400 to $1200 \mathrm{MPa}$ are included. Comparing the zones for these range of materials to zones $A$ and $B$, it is obviously unrealistic to assume that structural behaviour of New RC structures can be understood simply by extrapolating the knowledge of ordinary RC structures. The area in Figure 2 for the New RC is further divided into four zones, namely zones I, II-1, II-2, and III. Structures in these zones will be studied and developed by somewhat different tactics. Experimental approach is indispensable, but in general, theoretical examination of experimental data will be emphasized in this project. Current technical knowledge on RC structures will also be re-examined.
In some zones in Figure 2, particularly in zone III, basic problems will have to be re-examined, and hence the project may not yield much practical results. Most practical results are expected in zones I and II-1, because these zones are relatively close to the boundary of the current technology, and simple extrapolation will be effective at least partially.

Objectives of Research and Development and Final Expected Results

The objectives of research and development and the corresponding final results expected in the project are summarized in Table 2. Results will be partly available to refine the current RC technology. In the table under the third objective, the word "guidelines" for structural design and construction do not mean a type of the guidelines that will give full details of technology, but it will give only basic principles for design and construction practice. Such a soft type of the guidelines is preferred at this stage of the game, as definite and detailed specification-type guidelines often tend to impede the development of relevant technology. 


\section{Research organization}

The Building Research Institute of the Ministry of construction is in charge of conducting the project. Research committees were set up in an organization called Japan Institute for Construction Engineering, to organize people from universities, Housing and Urban Development Corporation, makers of cement, admixtures, and steel, and construction companies.

Under the Technical Coordination Committee, five technical committees were installed. They are in charge of making research programs in detail, implementing research works, and integrating research results in five particular fields. The names of these committees are: Concrete committee, Reinforcement Committee, Structural Element Committee, structural Design Committee, and Construction and Manufacturing Committee, to start in 1991. Technical committees organize working groups as needed.

\section{Items for Research and Development}

Following research items were assigned to each technical committees at the onset of the project.

\section{For the concrete committee:}

(1) Development of materials necessary for making high-strength and super high-strength concrete. Quality standards of the materials.

(2) Physical properties of high-strength and super high-strength concrete.

(3) Mix proportion design, casting and curing works and quality control.

\section{For the Reinforcement Committee:}

(1) Development of high-strength and super high-strength steel bars. Mechanical properties of steel bars.

(2) Mechanical properties of confined concrete.

(3) Constitutive equations for RC elements and application of finite element method.

(4) Bond between concrete and steel bars Anchorage and arrangement of steel bars.

\section{For the Structural Element committee:}

(1) Mechanical properties of beams and columns.

(2) Mechanical properties of shear walls.

(3) Effect of shear force on beams, columns, and shear walls.

(4) Mechanical properties of beam-column joints and frames.

(5) Mechanical properties of foundations.
For the Structural Design Committee:

(1) Methods for modelling and analysis of structural frames in each zone.

(2) Practically feasible types of structure

loads and remirements

(3) Design seismic loads and requirements for structural performance.

(4) Design methodology.

For the construction and Manufacturing comittee, research items are to be established in 1991.

\section{Major Research Topics}

One of the most fundamental and important topics is the ductility of high-strength reinforced concrete. High-strength concrete has been used mainly as countermeasure to high axial stress in the lower story columns of highrise buildings. Maximum number of stories of highrise RC buildings is almost completely determined in practice by the concrete strength, such as 25 stories for 36 $\mathrm{MPa}$, or 30 stories for $42 \mathrm{MPa}$. From the viewpoint of axial column stress, higher concrete strength is the most vital element in order to realize higher buildings.

However, it has been pointed out that the falling branch of stress-strain curve of high-strength concrete is more pronounced, and further it is more difficult to improve the falling branch ductility by lateral confinement. It is necessary to develop the most effective method of lateral confinement, and at the same time, to recognize the limitation of improved ductility by means of lateral confinement.

Another problem related to the ductility of high-strength reinforced concrete is the property of high-strength steel. At present super high-strength steel bars of $1300 \mathrm{MPa}$ specified yield strength are used very frequently in practice for lateral shear reinforcement, but they have never been used as longitudinal reinforcement. In order for high-strength steel bars to be used as longitudinal reinforcement, their quality in terms of stress-strain relationship should be improved. The most important practical problem is how much improvement can be specified and realized by steel manufacturers. In the long run, the ductility of New RC members will have to be lower than ordinary RC members, and hence it will be necessary to develop design philosophy which depends more on strength, but less on ductility, of constituent materials.

Bond between concrete and reinforcing bars is another basic issue in New RC. Demand on bond increases in proportion to the increase of yield strength of steel bars, but the bond capacity does not increase in proportion to the increase of concrete strength. Thus the bond becomes one of the critical problems of New RC structures. In particular, resistance against bond splitting failure is an important subject for bar development. 
Final expected results

objectives

1) Development of high-strength and high-quality materials

2) Evaluation of properties of members and frames

3) Development of design and construction guidelines

4) Feasibility study on RC buildings in Zone II-1

5) Feasibility study on RC buildings in Zone III Construction guideline
For New RC

Methods for mix proportion method and quality control of concrete (Zone I)

Methods for production and arrangement of reinforcements (Zone I)

Guidelines for develop-

ing materials for zone II and III

Methods of analysis

Structural design guideline (Zone I) (Zone I)

Draft guidelines for structural design and construction (Zone II, III)

New type high-rise buildings

New images of $R C$ buildings
For current RC

Revision of design method for mix proportion and quality control method for concrete

Revision of reinforcement quality standards

Revision of upper limits

of reinforcement

strength

Revision of current methods of analysis

Revision of structural design methods

Revision of construction standards
Use of high strength materials usually results in a reduction of cross section of members, thus reduction of stiffness of members and structures. Among structural design criteria listed in Table 1, that for the drift angle governs in most highrise RC buildings even at present, and it is expected to be more so for New RC buildings if the same design criteria as in Table 1 are maintained. Since the design criterion for drift was established not on any rational basis, it is not easy to challenge for its revision by a rational discussion. But the author believes that we will have to start discussing on it seriously, sooner or later.

\section{CONCLUSION}

In this paper the author first reviewed the present state-of-the-art of the seismic design of highrise RC buildings in Japan. The quick development of highrise RC construction owes to many factors, but availability of high strength materials was the most fundamental factor that enabled the development. In the second part of the paper, the author outlined a Japanese national research project entitled "Development of Advanced RC Buildings using High-strength Concrete and Reinforcement (New RC)". It is a Project to try to develop high-strength and super high-strength materials for RC structures, and to provide necessary design aids for highrise and other new RC structures. It is expected that by 1993 our knowledge on the reinforced concrete will be substantially enlarged.

\section{REFERENCES}

1. Aoyama, H., Murota, T. Hiraishi, H. and Bessho, S. 1990. Outline of the Japanese national project on advanced reinforced concrete buildings with high-strength and high-quality materials, 2nd Int'l Symp. on Utilization of High-Strength Concrete, Berkeley, CA.

2. Architectural Institute of Japan (AIJ) 1990. Design guidelines for earthquake resistant reinforced concrete buildings based on ultimate strength concrete. Tokyo.

3. Building Center of Japan (BCJ). 1986 on the earthquake motions for use in dynamic response analysis of highrise buildings, Building Letter, 6, 49-50. Tokyo. 